\title{
Auto-Graded Chemical Equation Problems in Online Blackboard Assessments
}

\author{
Jimoh Tijani* \\ Department of General Studies, Jubail Industrial College, P. O. Box 10099, Jubail Industrial City 31961, Saudi Arabia \\ *Corresponding author: tijani_j@jic.edu.sa
}

\begin{abstract}
This article describes the development and implementation of auto-grade online chemical equation questions, created by using Fill in Multiple Blanks question options on the Blackboard Software. Five categories of questions other than multiple choice questions were effectively implemented in online assessments. This kind of questions may be used for large class online home works, tutorials, and proctored-quizzes.
\end{abstract}

Keywords: general chemistry, chemical equations, online-homework, blackboard, assessments, auto-graded, fill in multiple blanks

Cite This Article: Jimoh Tijani, “Auto-Graded Chemical Equation Problems in Online Blackboard Assessments.” World Journal of Chemical Education, vol. 5, no. 3 (2017): 91-93. doi: 10.12691/wjce-5-3-2.

\section{Introduction}

Homework for a very large group of students has quite number of challenges that ranges from difficulties in grading [1] to problems of students copying each other without actually solving the questions themselves. The advent of the internet age has made the use of online homework has become more commonplace in General Chemistry course. [2] Online homework has been shown to have clear advantages over the traditional paper homework to increase efficiency in distributing, collecting and grading. [3]

Multiple-choice questions (MCQs) are the predominate form for practical applications of online knowledge assessment, even though there are indications that this form of assessment predominantly tests only lower levels of cognitive skills. [4] MCQs mainly stimulate the appearance of surface learning strategy. On the other hand, online assessments in the form of an essay mainly stimulate the appearance of deep learning strategy. [4]

This paper focused is on how to create auto-graded online chemical equation questions, which are not MCQs, by using Blackboard Fill in Multiple Blanks options. Solutions to some limitations and problems were also discussed therein. The questions are part of online homework questions successfully deployed to our students, numbering 350-450 students per semester, in the last two semesters, by the Department of General Studies of Jubail Industrial College, Jubail, Saudi Arabia.

\section{Fill in Multiple Blanks and Chemical Equations}

For Fill in Multiple Blanks questions, students are presented with text containing up to 10 blanks, in which they type appropriate words, phrases or numbers. Student's answers are graded automatically, by matching with answers already provided by the instructor. [5]

The potential types of questions are:

1. Balancing numerical in chemical equations

2. Completing and balancing one product

3. Completing and balancing two products

4. Converting word questions to chemical equations

5. Classifying chemical reactions.

i. Balancing numerical in chemical equations

There is no sequence of rules that can be followed blindly to get a balanced chemical equation. All we can do is manipulate the coefficients written in front of the formulas of reactants and products, until the number of atoms of each element on both sides of the equation are the same [6] (numerical balancing).

\section{QUESTION 1}

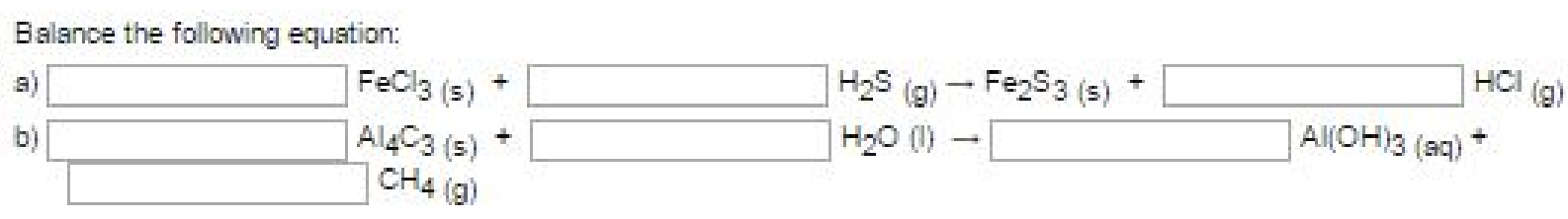




$$
3 \mathrm{FeCl}_{3(\mathrm{~s})}+3 \mathrm{H}_{2} \mathrm{~S}_{(\mathrm{g})} \rightarrow \mathrm{Fe}_{2} \mathrm{~S}_{3(\mathrm{~s})}+6 \mathrm{HCl}_{(\mathrm{g})} .
$$

The stoichiometric coefficient of $\mathrm{Fe}_{2} \mathrm{~S}_{3}$ Question 1a is 1, leaving cell without a variable also implied 1 , but the Blackboard Fill in Multiple Blanks does not accept blank, a variable should be written in the blank (cell), therefore, we have to provide the value 1 as in Question 1b (coefficient of $\mathrm{Al}_{4} \mathrm{C}_{3}$ ), or not providing a cell, as in question 1a (coefficient of $\mathrm{Fe}_{2} \mathrm{~S}_{3}$ ), Figure 1 .

\section{ii. Completing and balancing one products}

In writing the product of combination reactions, compounds should be represented by their correct chemical formulas, which are written on the basis of valences (i.e. combining capacities of the interacting elements or charges of their ions). [7] For example in Question 2a, aluminum has a valence of +3 and oxygen a valence of +2 , so the formula of aluminum oxide is $\mathrm{Al}_{2} \mathrm{O}_{3}$. One limitation of the Blackboard is the inability of the examinees to write the number of atoms in the subscript forms.

In addition reactions, products should be written in their molecular formulas (compounds are written by grouping the atoms of the same elements together). For example, the molecular formula of ethanol is $\mathrm{C}_{2} \mathrm{H}_{6} \mathrm{O}$. However, Chemist often writes it condensed molecular formula as $\mathrm{CH}_{3} \mathrm{CH}_{2} \mathrm{OH}$ (or in a more abbreviated for as $\mathrm{C}_{2} \mathrm{H}_{5} \mathrm{OH}$ ). This kind of representation tells us how atoms in the molecules are linked. [8] The other possible answers provided by the examiner on this questions are: $\mathrm{HOCH}_{2} \mathrm{CH}_{3}, \mathrm{CH}_{3} \mathrm{CH}_{2}-\mathrm{OH}, \mathrm{HO}-\mathrm{CH}_{2} \mathrm{CH}_{3}, \mathrm{CH}_{3}-\mathrm{CH}_{2}-\mathrm{OH}$, $\mathrm{CH}_{2}(\mathrm{OH}) \mathrm{CH}_{3}, \mathrm{C}_{2} \mathrm{H}_{5}-\mathrm{OH}$, etc. To avoid difficulties, the answer needs to be kept simple and brief, ${ }^{5}$ however the simple molecular formula $\left(\mathrm{C}_{2} \mathrm{H}_{6} \mathrm{O}\right)$ is the best option (Figure 2).

\section{iii. Completing and balancing two products}

The problem that could arise in completing and balancing two products is deciding which of the product will be written first, this problem can be solved if the states of the products are different, which is the case in most of the reactions. Therefore the product that should be written first is directed by the state. In question $3, \mathrm{CO}_{2}$ will come first before water, because of the state of $\mathrm{CO}_{2}(\mathrm{~g})$ was place in the first cell, Figure 3 . The limitation of typing subscript is present here too.

\section{iv. Converting word questions to chemical equations}

In Question 4, reactants are $\mathrm{Ca}(\mathrm{OH})_{2}$ and $\mathrm{HNO}_{3}$, both reactant states are aqueous (aq), the problem is which of the reactants should be written first, the way out of this is to provide both answers (variables, $\mathrm{Ca}(\mathrm{OH})_{2}$ and $\mathrm{HNO}_{3}$ ) in both blacks, as it is very unlikely for examinee to write acid or base in both cells, Figure 4. The subscript limitation is also a problem in this type of questions.

\section{v. Classification of chemical reactions}

Several general types of chemical reactions can occur based on what happens when going from reactants to products. [9] Combustion reactions can easily be identified by the presence of $\mathrm{O}_{2}$ on the reactant side, $\mathrm{CO}_{2}$ and $\mathrm{H}_{2} \mathrm{O}$ on the product side, Question 5a.

The variables that can be provided for Question $5 \mathrm{~b}$ by the examiner are combination, synthesis or addition. A more active element displaces another less active element in a compound hence the answers provided by the examiner to Question 5c could be replacement, single replacement, displacement or substitution (reactions), Figure 5.

\section{QUESTION 2}

\section{Pridict the product and balance the combination and addition reactions:}

a) combination reaction

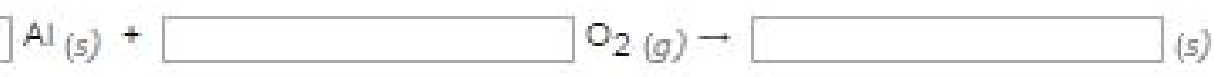

b) addition reaction

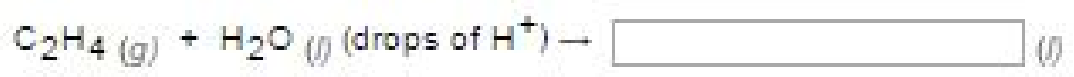

Figure 2.

\section{QUESTION 3}

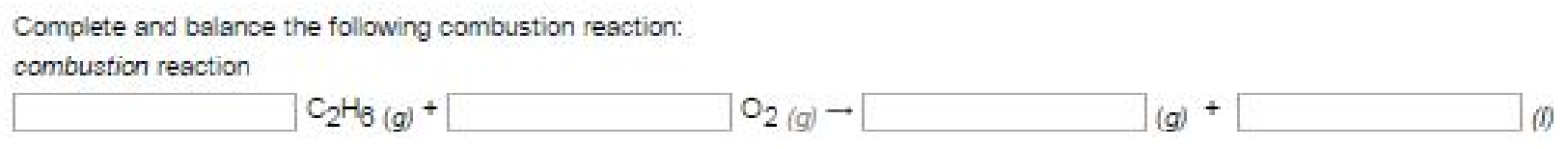

Figure 3.

\section{QUESTION 4}

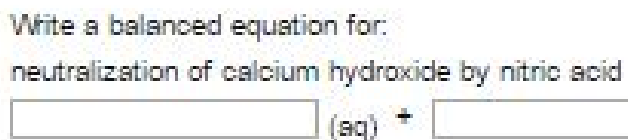

Write a balanced equation for:
neutralization of calcium hydroxide by nitric acid (ac) + (aq) $\rightarrow$

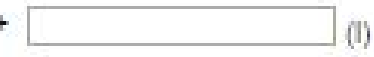

Figure 4. 


\section{QUESTION 5}

\section{Classify the following chemical reactions:}

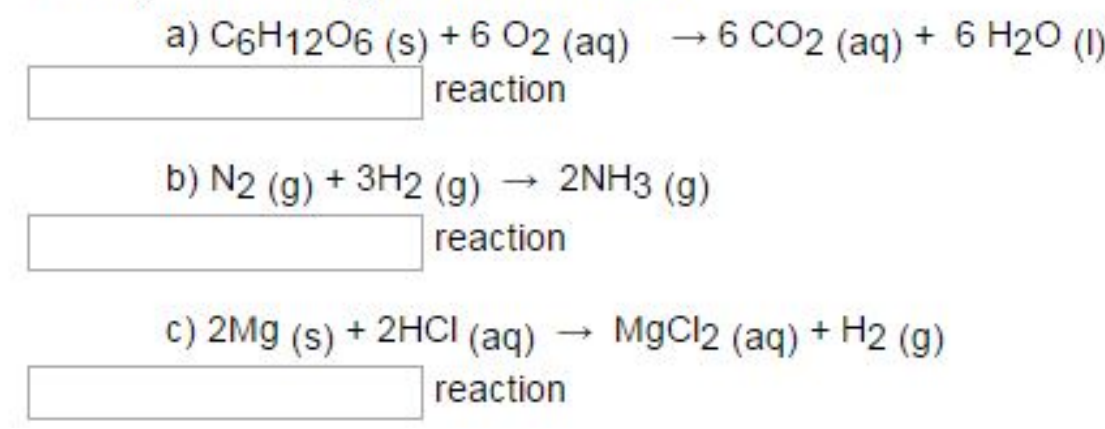

Figure 5.

\section{Limitations}

- Inability of the examinee to write subscripts for the number of atoms in the chemical formulas.

- The cells cannot be left without variables even if the coefficient in the equation is 1 .

- Lack of control on the size of the cells.

\section{Associate Content}

Pdf file for the sample questions is available on the internet. Step by step on how to create Fill in Multiple Blank Questions can be found in reference [5].

\section{Acknowledgments}

Facilities provided by Jubail Industrial College of Royal Commission for Jubail and Yanbu are gratefully acknowledged. The author is grateful to Dr. Yunusa Umar and Mr. Rizan Abdul Rahid for their help during preparation of the manuscript.

\section{References}

[1] Parker, L. L, Loudon G. M, Case Study Using Online Homework in Undergraduate Organic Chemistry: Results and Students Attitudes. J. Chem. Educ. 2013, 90, 37-44.

[2] Jack F. E, Junelyn P, Online Homework Put to the Test: A Report on the Impact of two Online Learning Systems on Student Performance in General Chemistry: J. Chem. Educ. 2013, 90, 1137-1143.

[3] Timothy, P. O, Grainne, C. H, Using Structural-Based Organic Chemistry Online Tutorials with Automated Correction for Practice and Review: J. Chem. Educ. 2014, 91, 1851-1854.

[4] Miran Z, Igor B, Dragutin K; Using Online assessments to Stimulate Learning Strategies and Achievement of Learning Goals, Computers \& education, 2015, 91 32-45.

[5] https://en-

us.help.blackboard.com/Learn/Instructor/Tests_Pools_Surveys/04 0_Question_Types/Fill_in_Multiple_Blanks_Questions (accessed March 2017).

[6] James N. S; George M. B; Lyman H. R Chemistry: Structure and Dynamics, John Wiley and sons. Inc, pg. 53.

[7] Doris K, Chemical Principles Revisited, The Chemical Equation Part I: Simple Reaction: J. Chem. Educ. 1978, 3, 184-189.

[8] Raymond C. Chemistry, Mc Graw Hill, $5^{\text {th }}$ edition, pg. 48.

[9] John T. M; Chemistry for Dummies, Wiley Publishing, Inc. $2^{\text {nd }}$ edition, pg. 114. 